\title{
HIV-1 Suppresses Notch-1 Expression in HPV-16+ CaSki Cells for Cancer Progression
}

Serena Judith DSouza ( $\nabla$ dsouzaserena17@rediffmail.com )

National AIDS Research Institute

Arati Mane

National AIDS Research Institute

Linata Patil

National AIDS Research Institute

Aazam Shaikh

National Centre For Cell Science

Madhuri Thakar

National AIDS Research Institute

Vandana Saxena

National AIDS Research Institute

Leila Fotooh Abadi

National AIDS Research Institute

Sheela Godbole

National AIDS Research Institute

Smita Kulkarni

National AIDS Research Institute

Raman Gangakhedkar

Division of Epidemiology and communicable diseases, ICMR

Padma Shastry

National Centre For Cell Science

Samiran Panda

National AIDS Research Institute

\section{Research Article}

Keywords: HIV-1, HIV-HPV co-infections, HIV-Tat, Notch-1, Cell cycle genes

Posted Date: May 12th, 2021

DOI: https://doi.org/10.21203/rs.3.rs-497573/v1 
License: (c) (i) This work is licensed under a Creative Commons Attribution 4.0 International License. Read Full License 


\section{Abstract \\ Background}

High Risk Human Papilloma Viruses (HR-HPV) recurrently infect women having Human Immunodeficiency Virus - 1 (HIV-1)infection. Transforming HPV E6 and E7 genes promote invasive cancers and interact with Notch-1 receptor. Concomitantly, HIV-1 Tat binds to EGF motifs within the Notch1 extracellular domain. HR-HPV infection activates Notch-1 signalling. Permissive HIV-1 entry into the cervix is allowed. Notch-1 inhibitors may offer solace to the aggressive cancer phenotype in HIV-1 positive women. Still, the molecular cross talk between different oncogenes within the Notch-1 pathway during HIV-1/HPV-16 ${ }^{+}$co-infections has not been elucidated.

\section{Methods}

Adherent cervical tumor derived cell lines-CaSki cell line (with inherent HPV16 ${ }^{+}$sequence and endogenous Notch-1 activity) and C33A cell line (cervical cancer phenotype, HPV -ve for HPV DNA and RNA) were used. Plasmids (pLEGFPN1 encoding HIV-1 Tat and pNL 4 - 3 encoding HIV-1(full HIV-1 genome), were transfected at $600 \mathrm{ng} / \mathrm{mL}$ into the above mentioned cell lines, in order to examine independent effects of HIV-1 Tat and HIV-1 transfection in HPV- $16^{+}$cervical cancer cells. We performed western blotting, cell cycle analysis and RT-qPCR post transfection. Three sets of independent experiments were analyzed by Graph Pad Prism 5. Statistical significance was calculated using Student $\mathrm{t}$-test. Data expressed as mean \pm standard deviation (SD). $p$ values $\leq 0.05^{*}$ were considered statistically significant.

\section{Results}

HIV-1 Tat and HIV-1 inhibited Notch-1 expression, with differential effects on EGFR when comparing C33A and CaSki cell lines. CDK2 induction in Tat transfected CaSki cells, showed concomitant $G_{0} / G_{1}$ phase accumulation favouring cancer progression. Notch-1 inhibition shut off significant Cyclin D expression with a significant p21 induction and increased $\mathrm{G}_{2}-\mathrm{M}$ cell population in CaSki cells. On the contrary, HIV-1 infection utilized Hes-1-EGFR-CyclinD-p21axis, $\mathrm{G}_{2}-\mathrm{M}$ arrest, DDR response and cancer progression.

\section{Conclusion}

Our study highlights for the first time that HIV-1 Tat and/or HIV-1 driven cancers in HPV- $16^{+}$CaSki cells, show Notch-1 suppression and CDK2 dependent activity. HIV-1 Tat activates Hes-1 amplifying the EGFR gene which improves the aggressive state possibly through irreversible oxidative-stress induced senescence. HIV-1, favours cancer progression through its CXCR4 receptor, responsible for unbridled mitosis, $\mathrm{G}_{2}-\mathrm{M}$ arrest and damaged DNA response (DDR). Treatment of CaSki cells with a Notch-1 inhibitor, DAPT showed marginal recovery in p21expression with $\mathrm{G}_{0} / \mathrm{G}_{1}$ and $\mathrm{S}$ phase recovery. 


\section{Background}

There is an increased risk of co-infections with human papilloma virus (HPV) with persistence of many carcinogenic subtypes in Human Immunodeficiency Virus (HIV-1)-positive women [1]. They are more prone to invasive cervical cancers too [2, 3]. Epidemiological studies from a cohort of HIV-1 positive women established an incidence of $35.3 \%$ carcinogenic human papillomavirus (HPV) genotypes. Oncogenic HPV-16 also escapes immune surveillance in HIV-1 positive women during combined antiretroviral therapy (cART) [4]. HPV vaccines have not yet been examined for the recurrence of cervical intraepithelial lesions in HIV-1 positive women [5].

HPV lifecycle orchestrates growth and differentiation events through HPV transforming genes-E6/E7 facilitating tumorigenesis [6]. During HIV-1 infection, the accessory protein Tat and HPV E6/E7 proteins exploit Notch signaling to exacerbate HPV-associated disease pathogenesis[7, 8]. Transmembrane Notch1 protein is essential for proliferation, differentiation and apoptosis at all stages of life. Notch-1 activation, through ligand binding from neighboring cell encounter, induces proteolysis and release of Notch-1 intracellular domain (NICD) into the nucleus, the main gene processing centre [8]. Concomitantly, Numb, an evolutionary conserved protein enhances Notch-1 signaling by repressing NICD ubiquitination [9]. NICD also binds with DNAbinding transcription factor protein, CSL to initiate Notch-1 downstream targets, Hes-1 and Hey-1 gene transcription associated with carcinogenesis and progression of cervical carcinoma [10]. Alternative spliced Numb iso variants, short (Numb S) and long (Numb L) also influence Hes-1 expression [10].

Notch-1, Numb and EGFR have similar roles in cell fate specifications including their involvement in cancers[11]. In-vitro studies in breast cancer cell lines demonstrated a positive link between Notch-1 and EGFR when transfected with HIV-1[12]. Notch-1 regulates growth and differentiation through cyclin D, CDK2 and p21 in cell lines like T-cell acute lymphoblastic leukemia [13]. Cervical cancer cells simultaneously utilize Notch-1 [14] as well as hyper-express CXCR4, a co-receptor of HIV-1. The cross interference of intricate pathways converge together viz CXCR4/Notch-1, Wnt/Notch-1, Notch1/Snail/Numb, Notch-1/EGFR etc are implicated in cancer progression, survival and chemotaxis via intracellular signaling /downstream mediators $[15,16]$.

Recurrent, invasive cervical carcinomas due to HIV-1 infection and interference with cell cycle marker expression, prompted us to examine the effects of HIV-1 Tat and full HIV-1 genome on HPV-ve C33A cells and HPV- $16^{+}$CaSki cells using transient transfection. We demonstrate here for the first time that both HIV-1 Tat and HIV-1 suppresses Notch-1 expression in CaSki (HPV-16 $\left.{ }^{+}\right)$cells through significant Hes1induction and increased CDK2 expression for $G_{0}-G_{1}$ accumulation at the expense of $S$ phase. HIV-1 Tat amplifies EGFR and p21 expression though Cyclin D is depleted, whereas HIV-1 transfection decreases EGFR and p21 expression concomitant with over active Cyclin D. Elevated Cyclin D preserves proliferation for unbridled mitosis, $\mathrm{G}_{2}-\mathrm{M}$ arrest, genomic instability and cancer progression $[17,18]$. Taken together, HIV-1Tat shows a positive cross talk between Notch-1 and EGFR which favors an aggressive phenotype whilst HIV-1 has a reverse link between Notch-1 and EGFR. (Fig. 5) 


\section{Materials And Methods \\ 2.1. Media and Experimental Reagents}

The primary antibodies for Notch-1 (ab65297), Hes-1(ab49170), EGFR (ab2430), CDK2 (ab235941,) and GAPDH (sc32233) were purchased from Abcam, UK and SantaCruz, USA. The DNA transfection reagent, Jet PEl was procured from GeneX, India. The Notch-1 inhibitor- $N$-[N-(3, 5-difluorophenacetyl)-Lalanyl]-S phenylglycine t-butyl ester (DAPT) was obtained from Abcam, UK. 3-(4, 5-dimethylthiazol-2-yl)-2, 5diphenyl tetrazolium bromide (MTT), Dimethyl sulfoxide (DMSO), Antibiotic antimycotic solution (100x), Ethanol, 2-Mercaptoethanol and 2-Propanol (Isopropanol) were obtained from Sigma, USA. Roswell Park Memorial Institute (RPMI) 1640, Dulbecco's Modified Eagle Medium (DMEM) and N-2-

hydroxyethylpiperazine-N-2-ethane sulfonic acid (HEPES-1M) were obtained from HiMedia Laboratories, India. The Fetal Bovine Serum (FBS) was obtained from Moregate, Australia. DNA was extracted using GF-1 Tissue DNA Extraction Kit from Vivantis Technologies, Malaysia. RNA isolation kit, Plasmid Miniprep Plus Purification Kit were procured from Gene Mark, USA. The Cycletest ${ }^{\text {TM }}$ Plus DNA kit was procured from, BD Biosciences, USA. Power SYBR® Green RNA to CT TM 1-Step Kit was procured from Thermofisher, USA.

\subsection{Cell lines}

Adherent cervical tumor derived cell lines HPV-Negative C33A cells (HPV -ve for HPV DNA and RNA having cervical cancer phenotype)and HPV $-16^{+}$CaSki cells(with inherent HPV- $16^{+}$and HPV- $18^{+}$ sequences and endogenous Notch-1), were used for transfection.

\subsection{Cell culture}

CaSki and C33A cell lines were procured from National Centre for Cell Sciences (NCCS), Pune. CaSki cell line was propagated in RPMI-1640 with sodium bicarbonate without L-Glutamine supplemented with 10 $\%$ fetal bovine serum and antibiotic, anti-mycotic solution. C33A cells were grown DMEM medium consisting of L-Glutamine, Sodium pyruvate, Glucose and Sodium bicarbonate.

\subsection{Plasmids}

The pLEGFPN1-(RV-Tat 86) plasmid was a gift from Dr. Francesca Peruzzi, Associate Professor, LSU Health Sciences, New Orleans $\mathrm{LA}_{\text {. The }} \mathrm{pNL}_{4.3}$, a full length replication competent, infectious HIV-1 subtype B, was obtained through NIH AIDS Reagent Program.

\subsubsection{Cell proliferation}

Briefly, CaSki and C33A cells (10\%/well) were seeded in 96micro well culture plates and maintained at $37^{\circ} \mathrm{C}$ in a $\mathrm{CO}_{2}$ incubator. Cells were exposed to serial dilutions of plasmid DNA/DAPT and incubated overnight for $24 \mathrm{hrs}$. MTT solution $(5 \mathrm{mg} / \mathrm{mL})$ was added to the plate and then incubated for $4 \mathrm{hrs}$. 
Supernatant was replaced with DMSO, and absorbance was measured at 550/630 nm. The viability was calculated in percentage with reference to control sets.

\subsubsection{Recombinant cloning}

Plasmids were transformed using $\mathrm{DH}-5 \mathrm{a}$ through heat shock $\left(42-45^{\circ} \mathrm{C}\right)$ and rapid chilling on ice. After heat shock treatment, the plasmid DH-5a mixture was added to pre-warmed SOC or LB without antibiotics. LB agar plate containing ampicillin were used to grow the transformed bacteria, at $32^{\circ} \mathrm{C}$. Colonies were further inoculated in $15 \mathrm{~mL}$ LB mixed with $65 \%$ glycerol for stock preparation and plasmid amplification.

\subsubsection{Plasmid Purification}

Briefly, bacterial cells were pelleted, resuspended in $250 \mu \mathrm{L}$ of Solution I ( as per the manufacturer's protocol-Gene Mark plasmid miniprep purification kit). With subsequent addition of $250 \mu \mathrm{L}$ Solution II, and following 4-5 times mixing, Solution III (250 $\mu \mathrm{L})$ was added. The spin columns containing lysate/s were centrifuged, rinsed and purged of purified DNA with preheated elution buffer. The DNA was quantified and stored at $-20^{\circ} \mathrm{C}$ for transfection.

\subsection{Transient Transfection}

Transfections were carried according to the manufacturer's instructions (jetPEI® DNA transfection reagent, USA). Briefly, CaSki and C33A cells were seeded in T-25 flasks ( 1 X $\left.10^{6}\right)$ with 5 ml medium containing FCS and antibiotics. Quantified DNA-Six hundred ng/mL DNA was used for transfecting one million cells[19]. The media was replenished the next day and cell lines maintained overnight in a $\mathrm{CO}_{2}$ incubator. Cells were detached for further analysis.

\subsection{Cell cycle analysis}

Transfected cells were scraped gently, washed twice in cold PBS and processed using BD Cycletest ${ }^{\mathrm{TM}}$ Plus DNA Kit as per the manufacturer's protocol. Briefly, cells were pelleted, mixed with Solution A (trypsin buffer) for 10 min followed by incubation with Solution B (trypsin inhibitor and RNase buffer) for 10 min. Finally the cells were stained with $200 \mu \mathrm{L}$ of cold Solution C (PI stain solution) kept for 10 min in the dark at $4{ }^{\circ} \mathrm{C}$ and analyzed for DNA content by BD FACSAria ${ }^{\mathrm{TM}}$ (BD, USA).

\subsection{DNA isolation}

DNA from transfected cells was isolated using the manufacturer's protocol (Vivantis Technologies, Malaysia). Briefly, the cell pellet ( $5 \times 10^{6}$ cells) was resuspended in PBS, treated with Proteinase $\mathrm{K}$ and lysis enhancer in Tris buffer. After incubation at $65^{\circ} \mathrm{C}$ for $10 \mathrm{~min}$ the cells were transferred to the column, followed by column washing with wash buffer. DNA was eluted with preheated elution buffer and quantified using spectrophotometer.

\subsection{Polymerase Chain Reaction (PCR)}


Notch-1 PCR was optimized with DNA isolated from human fetal buccal mucosal (FBM) cell line procured from ACTREC, Navi Mumbai, India. Twenty $\mu \mathrm{L}$ reaction mix (1.2 $\mu \mathrm{L}$ DNA template, primer mix and PCR dye master mix (5Xia)) was subjected to the following conditions; $95^{\circ} \mathrm{C}$ for $4 \mathrm{~min}, 45$ cycles at $95^{\circ} \mathrm{C}$ for 20 secs, $60^{\circ} \mathrm{C}$ for 20 secs, two extension steps $-72^{\circ} \mathrm{C}$ for 20 secs and 2 mins. Notch- 1 PCR protocol was also used for CaSki cells.

Tat PCR was performed with DNA isolated from CaSki and C33A cells using the following conditions; 95 ${ }^{\circ} \mathrm{C}$ for 9 mins followed by 34 cycles at $95^{\circ} \mathrm{C}$ for $1 \mathrm{~min}, 53^{\circ} \mathrm{C}$ for 2 mins, two extension steps at $72{ }^{\circ} \mathrm{C}$ for 1 min and 7 mins respectively. PCR products were resolved on a $2.0 \%$ agarose gel and visualized on a UV transilluminator after staining with ethidium bromide.

\subsection{Western blot analysis}

C33A and CaSki cells were harvested, washed, and lysed with RIPA buffer supplemented with phenylmethylsulfonyl fluoride (PMSF). Protein extracts $(30 \mu \mathrm{g})$ per sample were subjected to $8 \%$ SDS-PAGE and transferred to polyvinylidene difluoride membranes (EMD Millipore, USA). Membranes were blocked with $5 \%$ nonfat skim milk for $1 \mathrm{~h}$ at room temperature, probed with the appropriate primary antibodies (Notch-1, Hes-1, CDK2, EGFR and GAPDH a endogenous protein) at 1:1000 dilution, washed, and then incubated with the corresponding goat anti-rabbit and anti-mouse secondary antibody (1:5000 dilution). The chemiluminescent signal was detected using ECL system (Intron, Seongnam, Korea). Semi-quantitative analyses of the intensities of the protein bands were analyzed by using ImageJ software $(\mathrm{NIH})$.

\subsection{RNA Isolation}

RNA was isolated from transfected cell lines as per the manufacturer's protocol (GeneMark Biolab, Thailand). Briefly, transfected culture cells were lysed with lysis methanol cocktail in $70 \%$ ethanol. The lysate was loaded on the spin column and washed. After DNAse treatment, the columns were washed again with wash buffer. Purified RNA (30-50 $\mu \mathrm{L})$ was collected, quantified by a NanoDrop 2000c (Thermo Fisher Scientific, USA) and processed for qPCR.

\subsection{Quantitative Real-time PCR (qRT-PCR)}

qRT-PCR was conducted using Applied Biosystems ${ }^{\text {TM }}$ Power SYBR ${ }^{\text {TM }}$ Green RNA-to-CT ${ }^{\text {TM }}$ One-Step Kit and ABI 7500 FAST v2.3 (ThermoFisher, Singapore) as per the manufacturer's instructions. The qRT-PCR master mix ( $10 \mu \mathrm{L})$ consisted of a cocktail of $5 \mu \mathrm{L}$ of $2 X$ SYBR Green Real-time PCR Master, $2 \mu \mathrm{L}$ primers forward and reverse, $0.08 \mu \mathrm{L}$, RNA template (up to $100 \mathrm{ng}$ ), $2 \mu \mathrm{L}$, RNAse free water and $0.92 \mu \mathrm{L}, \mathrm{RT}$ Enzyme $(125 \mathrm{X})$. The thermal cycling conditions were $48^{\circ} \mathrm{C}$ for $30 \mathrm{mins}$, followed by 1 cycle at $95^{\circ} \mathrm{C}$ for $10 \mathrm{~min}, 45$ cycles at $95^{\circ} \mathrm{C}$ for $15 \mathrm{sec}, 60^{\circ} \mathrm{C}$ for $10 \mathrm{secs}$, and $72^{\circ} \mathrm{C}$ for $30 \mathrm{secs}$. Experiments were run in triplicates with $\beta$-actin as housekeeping gene. Relative concentrations were calculated using 7500 FAST software v2.3. Cycle threshold $\left(\mathrm{C}_{\mathrm{T}}\right)$ values of transfected C33A cell line (an $\mathrm{HPV}^{-}$cell line) served as the internal control for normalizing sample variations. The forward and reverse primers used for qRT-PCR 
were human Notch-1, Hes-1, Hey-1, cyclin D, CDK2, p21, EGFR, and $\beta$-actin represented in supplementary Table 1.

\subsection{Densitometry and statistical analysis}

The results were analyzed by Graph Pad Prism 5. Student $t$-test was used to determine the statistical significance of the data expressed as mean \pm standard deviation (SD). $p$ values $\leq 0.05^{\star}$ were considered statistically significant.

\section{Results}

\subsection{Effect of HIV-1 Tat transfection on CaSki cells}

HIV-1 Tat maintained the viability of C33A and CaSki cells at $37^{\circ} \mathrm{C}$. HIV-1 Tat significantly inhibited Notch-1 activity as observed by the downstream transcriptional activator, Hes-1 hyperexpression in CaSki cells (Fig. 1B,* $p \leq 0.05$ ). For WB analysis, four proteins (Notch-1, Hes-1, EGFR and CDK2) were normalized with the GAPDH protein. Protein levels were plotted as the densitometric ratio of CaSki + HIV-1 Tat $(600 \mathrm{ng} / \mathrm{mL}$ ) versus CaSki only (Fig. 3A). Hey-1, (Fig. 1C), the downstream Notch-1 transcriptional repressor was significantly suppressed following transfection with Tat (C33A mock vs CaSki mock * $p \leq$ 0.05; C33A $600 \mathrm{ng} / \mathrm{mL}$ vs CaSki $600 \mathrm{ng} / \mathrm{mL}$ * $\mathrm{p} \leq 0.05$ ). Although HIV-1 Tat suppressed Notch1expression, EGFR was significantly upregulated when C33A and CaSki cell lines were compared (Fig. 1D, ${ }^{\star} \rho \leq 0.05$ ). CDK2 induction (Fig. 1F, * $p \leq 0.05$ ) in Tat transfected CaSki cells, showed concomitant $\mathrm{G}_{0} / \mathrm{G}_{1}$ phase accumulation $(60.8 \% ; 66.20 \%$; supplementary Table 2$)$ when compared to HPV-ve C33A cells (55.9\%: $81.55 \%, * \leq 0.05)$. Cyclin D expression was significantly shut down in Caski $\left(\mathrm{HPV}-16^{+}\right)$cells (Fig. 1E) which coincided with a significant p21 induction (Fig. 1E \& G) as well as increased cell numbers in CaSki G ${ }_{2}-\mathrm{M}$ ( $12.3 \%$; supplementary Table 2$)$ phase cells.

\subsection{Notch-1 activation explains aberrant mitosis in CaSki cells during HIV-1 transfection}

HIV-1 maintained the viability in C33A and HPV- $16^{+}$CaSki cells at $37^{\square} \mathrm{C}$. Figure 2Aand $2 \mathrm{~B}$ shows significant inhibition of Notch-1 expression, though its downstream target Hes-1 was overexpresssed in HPV-16 ${ }^{+}$CaSki cells ( ${ }^{*} p \leq 0.05$ ) indicative of Notch-1 signalling. Notch-1 and Hes-1 proteins decreased and matched with the qPCR profile (Fig. 3B). HIV-1 also significantly inhibited Notch-1 transcriptional repressor Hey-1 (Fig. 2C). Interestingly, HIV-1 induced reverse expressions of EGFR (Fig. 2D) and Cyclin D (Fig. 2E) as that of HIV-1Tat (Fig. 1D \& 1E). EGFR inhibition affects $\mathrm{G}_{1}$ phase of the cell cycle, whereas overactive Cyclin $D$ permits cellular differentiation and cancer progression. Additionally, overactive Cyclin D showed hyper CDK2 (Fig. 2F) expression corroborating increased $G_{0} / G_{1}$ cell accumulation. EGFR and CDK2 (Fig. 3B) protein levels overlap with the qPCR data.HIV-1 transfection of CaSKi cells showed significant $G_{0} / G_{1}$ phase cell accumulation ( $p \leq 0.05 ; 78.35 \%$; supplementary Table 3 ) compared with 
C33A cells $(60.5 \%)$. A significant decrease in the $\mathrm{G}_{2}-\mathrm{M}$ cell population $\left(4.65 \%\right.$; ${ }^{*} \mathrm{p}<0.05$; supplementary Table 3)was observed in CaSki cells as compared to HPV-C33A cells ( * $p \leq 0.05$; supplementary Table 3). Consequent to $G_{2}-M$ arrest (supplementary Table 3 ) which collates with $p 21$ (* $p \leq 0.05$; Fig. $2 G$ ) shut down, HIV-1 transfection confirmed transcriptional Hes-1mediated $\sim$ p21 repression in a bHLH domain dependent manner plausibly promoting Cyclin $D$ induction. Excess Cyclin $D$ forming complexes with CDK2, DNA Damaged response (DDR), genomic instability, subsequent DNA repair, unscheduled aberrant mitosis and cancer progression.

\subsection{Incubation with Notch 1 inhibitor rescued p21expression}

CaSki cells were incubated with $62.5 \mathrm{mM} / \mathrm{L}$ DAPT to assess the effects of Notch-1 blockade on proliferation of HPV- $16^{+}$CaSki cells. MTT assay showed suppression of Notch- 1 which affected the growth and proliferation of CaSki cells (supplementary data). qPCR data demonstrated a significant decreased expression for Notch-1, Hes-1, Hey-1 and EGFR gene 24 hours post incubation of DAPT with CaSki cells ( ${ }^{*} p \leq 0.05$; Fig. $4 \mathrm{~A}$ ) as compared with solvent control. Cell cycle analysis also showed $\mathrm{G}_{0} / \mathrm{G}_{1}$ arrest in DAPT -treated CaSki cells ( supplementary Table 4). Consistent with $G_{0} / G_{1}$ arrest, cyclin $D$ (* $p \leq$ 0.05 ; Fig. 4B) was maintained, with significant p21restoration- (* $\mathrm{p} \leq 0.05$ Fig. 4B), and significant appreciable CDK2 expression. ( $\mathrm{p} \leq 0.05$; Fig. 4B).

\section{Discussion}

Notch family genes, crucial to normal embryogenesis are also implicated in cancers [20]. In HIV-1 /HPV co-infected women with cervical carcinoma, extracellular HIV-1 Tat clinically correlates with an aggressive carcinoma phenotype [21]. In HPV associated cancers, Notch-1 inhibition induces malignant transformation [6, 22]. In our study, we report for the first time that HIV-1 Tat significantly elicited Notch-1 inhibition in HPV- $16^{+}$CaSki cells through activation of Notch-1 signaling pathway, characterized by downstream target genes- Hes-1 transcriptional activator, and Hey-1, transcriptional repressor. Hey-1, appears to be depleted in CaSki cells a possible characteristic of transformed cell lines. Based on our data, we propose that HIV-1 Tat plausibly binds to EGF repeats on the extracellular Notch-1domain [22], consequently suppressing Notch-1 expression. Hes-1 and Hey-1 genes are involved in adhesion, invasion, angiogenesis and proliferative events during carcinogenesis [23, 24]. In T-cell leukemia, Hes-1 binds to the nuclear Cyclin D promoter to elicit Notch-1signaling. But, Hes-1 induction and Cyclin D repression are obligatory for sustenance and cancer progression in T-cell leukemia. Our observations in HIV-1 Tat transfected HPV-16 ${ }^{+}$CaSki cells, corroborate the above studies [23, 25]. HIV-1 Tat significantly induces Hes-1 expression for Cyclin D shut down ( ${ }^{*} p \leq 0.05$ ), with suppression of EGFR. Now, EGFR, the transcriptional target of Notch-1 [26], cooperates with downstream targets Cyclin D and CDK2 for growth, proliferation and cell cycle progression [27]. Additionally, Cyclin D, affiliated as downstream target of multiple oncogenic pathways, is also implicated in $G_{1}$ cell cycle progression. Cell cycle analysis demonstrate that HIV- 1 Tat significantly activates EGFR with consequent significant $\mathrm{G}_{0} / \mathrm{G}_{1}$ phase cell 
accumulation (* $p \leq 0.05$; supplementary Table 2 ) in HPV- $16^{+}$CaSki cells as compared with the HPV-, C33A cells. Recent evidences highlight that Cyclin D depletion disturbs oxidative balance in cancer cells. Subsequently, cancer cells succumb to high lethal oxidative stress inducing irreversible senescence [27]. Hence, HIV-1 Tat adjusts the tumor microenvironment to maintain the proliferative state to evade irreversible senescence through Hes-1 activation, EGFR and p21 amplification driving cell migration and invasion for an aggressive less therapeutic phenotype in HPV $-16^{+}$CaSki cells $[28,29]$. The above qRT-PCR data significantly collates with cell cycle $\mathrm{G}_{2}-\mathrm{M}$ phase population of HPV-16 ${ }^{+}$CaSki cells with HPV-C33A cells $\left({ }^{*} p \leq 0.05\right)$.

HIV-1, significantly (** $p \leq 0.005$ ) inhibits Notch-1 and Hey-1 expression though its downstream transcriptional activator Hes-1 $(* p \leq 0.05)$ was over expressed. Concomitantly, an oscillatory gene expression between Hes-1 and EGFR following HIV-1 infection indicates a plausible crosstalk between Notch-1 and EGFR pathways [12, 25]. As reported earlier, Hes-1 and Cyclin D gene expressions manipulate cancer maintenance and progression[24]. EGFR suppression and significant hyperactive CDK2 corroborate with cell cycle data showing significant $G_{0} / G_{1}$ phase cellular accumulation/s at the expense of $S$ phase (supplementary Table $3 ;{ }^{*} p \leq 0.05$ ) for cancer progression. Excess CDK2 forms nuclear complexes with Cyclin D, disturbing cell cycle progression [27]. Significant CDK2 hyper expression $(* \mathrm{p} \leq$ 0.05 ) and subsequent $p 21$ shut down ( $\mathrm{p} \leq 0.05$; Fig. $2 \mathrm{~F}, 2 \mathrm{G}$ ), decline in polyploid $\mathrm{G}_{2}-\mathrm{M}$ phase HPV-16 ${ }^{+}$ CaSki cells (4.65\%; (* $p \leq 0.05$; supplementary Table 3 ) was observed (data not shown) [27, 28, 29]. HIV-1 $\mathrm{Vpr}$ (Viral Protein $\mathrm{R}$ ) transcription causes $\mathrm{G}_{2}-\mathrm{M}$ of the cell cycle arrest inhibiting cell proliferation [30]. Additive effects of HIV-1 Vpr and Notch-1/ CXCR4 [16] partner together to inhibit p21 and juxtapose aberrant mitosis, $\mathrm{G}_{2}-\mathrm{M}$ arrest for induction of replication restart [31] for metastasis and cancer progression.

Our results with DAPT, a drug induced Notch-1 inhibitor and $y$-secretase blocker revealed significant recovery in the $G_{0} / G_{1}$ and $S$ phase HPV- $16^{+}$CaSki cells (supplementary Table 4). Notch-1 inhibition was approximately $35 \%$ ( ${ }^{*} \mathrm{p} \leq 0.05$; Fig. $4 \mathrm{~A}$ ). Downstream targets Hes-1 \& Hey-1 were significantly inhibited (* $p \leq 0.05$; Fig. $4 A$ ). There was a marginal recovery in $p 21$ expression ( ${ }^{\star} p \leq 0.05 ;$ Fig. $4 B$ ). DAPT rescues $\mathrm{G}_{0} / \mathrm{G}_{1}$ (* $\mathrm{p} \leq 0.05$; supplementary Table 4 ) and $\mathrm{S}$ phase ( $\mathrm{*} \leq 0.05$; supplementary Table 4) during HPV carcinogenesis.

\section{Conclusion}

Our results describe a negative link between Notch-1and EGFR during HIV-1 induced cancer progression. Tailor-made drug paradigms for clinical interventions may possibly inhibit an aggressive phenotype during cancer progression.

\section{List Of Abbreviations}




\begin{tabular}{|c|c|c|}
\hline 1 & HIV1 & Human Immunodeficiency Virus subtype 1 \\
\hline 2 & HPV & Human Papilloma Virus \\
\hline 3 & E6/E7 & Viral oncogenes (Early) of human papilloma virus \\
\hline 4 & HR-HPV & High Risk Human Papilloma Virus \\
\hline \multirow[t]{2}{*}{5} & Hes-1 & Transcriptional repressor- downstream target of Notch1 \\
\hline & & Hairy enhancer of Split-1 \\
\hline 6 & Hey-1 & Hairy/enhancer-of-split related with YRPW motif protein 1 \\
\hline 7 & EGFR & Epidermal Growth Factor Receptor \\
\hline 8 & CDK2 & Cyclin Dependent Kinase-2 \\
\hline 9 & Tat & Transactivator of Transcription \\
\hline 10 & Vpr & Viral Protein $\mathrm{R}$ \\
\hline 11 & CXCR4 & G-protein coupled chemokine receptor used by HIV to infect $\mathrm{CD} 4^{+} \mathrm{T}$ cells \\
\hline 12 & $\begin{array}{l}\text { CaSki } \\
\text { cell line }\end{array}$ & $\begin{array}{l}\text { Adherent epithelial cell line having inherent } 600 \text { copies of HPV }-16^{+} \text {and HPV- } 18^{+} \\
\text {sequences and with Notch-1 activity }\end{array}$ \\
\hline 13 & $\begin{array}{l}\text { C33A } \\
\text { cell line }\end{array}$ & Adherent epithelial cell line having cervical cancer phenotype but HPV ${ }^{-}$ \\
\hline 14 & FBM & Foetal Buccal Mucosal Cells \\
\hline 15 & FBS & Foetal Bovine Serum \\
\hline 16 & DAPT & $\mathrm{N}$-[N-(3,5-difluorophenacetyl)-Lalanyl]-S-phenylglycine t-butyl ester \{Notch1 inhibitor\} \\
\hline 17 & DDR & Damaged DNA Response \\
\hline 18 & MTT & 3-(4,5-dimethylthiazol-2-yl)-2,5- diphenyltetrazolium bromide \\
\hline 19 & DMEM & Dulbecco's Modified Eagle Medium \\
\hline 20 & $\begin{array}{l}\text { RPMI- } \\
1640\end{array}$ & Roswell Park Memorial Institute \\
\hline 21 & DMSO & Di methyl sulphoxide \\
\hline 22 & SOC & $\begin{array}{l}\text { Microbial growth medium used for the transformation of } \\
\text { competent cells (E. coli) }\end{array}$ \\
\hline 23 & $\begin{array}{l}\text { LB } \\
\text { broth }\end{array}$ & Lysogeny broth / Luria-Bertani medium \\
\hline 24 & PBS & Phosphate buffered saline \\
\hline 25 & PMSF & Phenylmethylsulfonyl fluoride \\
\hline
\end{tabular}




\begin{tabular}{|lll|}
\hline 1 & HIV1 & Human Immunodeficiency Virus subtype 1 \\
\hline $\mathbf{2 6}$ & $\begin{array}{l}\text { RT-PCR } \\
\text { or qPCR }\end{array}$ & Real Time or quantitative Polymerase Chain Reaction \\
\hline 27 & P21 & $\begin{array}{l}\text { A potent cyclin-dependent kinase inhibitor }(\mathrm{CKI}) \text { which binds and inhibits } \mathrm{CDK} 2, \\
\text { CDK1 activity, during cell cycle progression from } \mathrm{G}_{1} \text { to } \mathrm{S} \text { phase. }\end{array}$ \\
\hline $\mathbf{2 8}$ & WB & Western blotting \\
\hline
\end{tabular}

\section{Declarations}

\section{Ethics approval}

ICMR-NARI institutional review board approved this research study. Waiver of consent (vide NARI/EC Protocol No.: 2015-15) for C33A and CaSki cell lines was also granted.

\section{Consent for publication}

No writing assistance was provided.

\section{Availability of the data and materials}

All data generated or analysed during this study are included in this published article and its supplementary information files. This information are available on request.

\section{Competing interest}

All authors have no conflicting interests to declare.

\section{Funding}

This work was supported by an extramural grant from the Indian Council of Medical Research (ICMR), New Delhi, India (no5/2-3/LDCE/2015-ECD-II)

\section{Authors contribution}

I. Conception and design of the study : Dr Serena D'Souza, Dr Aarti Mane, Dr Smita Kulkarni and Dr Raman Gangakhedkar

\section{II.Experiments performed:}

a. Plasmid Cloning, Expansion and Isolation of Plasmid DNA: Dr Serena D'Souza

b. Gel electrophoresis: Mrs Linata Patil

c. Protein extraction, quantitation and western blotting: Mr Aazam Shaikh, Dr Serena D'Souza and Dr Padma Shastry 
d. MTT Assay/s:Ms Leila Fotooh Abadi, Dr Smita Kulkarni

e. Transfection of cell lines: Dr Serena D'Souza,

f. DNA isolation from mock and transfected cell lines: Mrs Linata Patil, Dr Serena D’Souza, Dr Aarti Mane

g. RNA isolation, quantitation and gel electrophoresis for RNA integrity : Dr Serena D'Souza

h. RT-PCR: Dr Serena D'Souza, Dr Madhuri Thakar

i. Experiments with Notch-1 inhibitor DAPT: Ms Leila Fotooh Abadi, Dr Serena D'Souza, Dr Samiran Panda

j. RNA isolation, quantitation and RT-PCR for cell lines with and without DAPT : Mrs Linata Patil, Dr Aarti Mane, Dr Serena D'Souza, Dr Samiran Panda

III. Collection and assembly of data: Dr Serena D'Souza, Dr Vandana Saxena, Dr Padma Shastry

IV. Data analysis and interpretation: Dr Serena D'Souza, Dr Sheela Godbole, Dr Vandana Saxena, Dr Padma Shastry

\section{Drafting the manuscript: Dr Serena D'Souza}

\section{Final approval of manuscript: All authors}

\section{Acknowledgements}

The authors gratefully acknowledge Drs VM Katoch and Soumya Swaminathan, Former- Director General/s ICMR, New Delhi for extramural support. Constructive discussions from Dr. Pradeep Seth, Chairman, Limited Department Competitive Examination (LDCE) committee, and Dr Madhu chhanda Das, Scientist D, ECD-II, ICMR are appreciated. Dr. SM Shahabuddin \& Mr Ajit Patil , Technical officer B, ICMR$\mathrm{NARI}$, are thanked for help with the cross-referencing and initial laboratory work respectively.

\section{References}

1. Godbole SV, Nandy K, Gauniyal M, et al. HIV and cancer registry linkage identifies a substantial burden of cancers in persons with HIV in India. Medicine. 2016;95:37.

2. Debeaudrap P, Sobngwi J, Marie-Pierre T, Clifford GM. Residual or recurrent precancerous lesions after treatment of cervical lesions in human immunodeficiency virus infected women: A systemic review and meta-analysis of treatment failure. Clin Infect Dis. 2019;69:1555-65.

3. Ryu A, Nam K, Kwak J, et al. Early human papillomavirus testing predicts residual/recurrent disease after LEEP. J Gynecol Oncol. 2012;23:217-25.

4. Mane A, Sahasrabuddhe VV, Nirmalkar A at al. Rates and determinants of incidence and clearance of cervical HPV genotypes among HIV-seropositive women in Pune, India. J Clin Virol. 2017; 88:26-32. 
5. Menon S, Rossi R, Kariisa M, Callens S. Determining the HPV vaccine schedule for a HIV-infected population in sub Saharan Africa- a commentary. Virol J. 2018;15:129.

6. Weijzen S, Zlobin A, Braid M, et al. HPV16 E6 and E7 Oncoproteins Regulate Notch-1 Expression and Cooperate to Induce Transformation. J Cell Physiol. 2003;194(3):356-62.

7. Nyagol J, Leucci E, Onnis A, et al. The Effects of HIV-1 Tat Protein on Cell Cycle during Cervical Carcinogenesis. Cancer Biology \& Therapy. 2006; $5684-90$.

8. Kovall RA, Gebelein B, Sprinzak D, et al. The Canonical Notch Signaling Pathway: Structural And Biochemical Insights Into Shape, Sugar, And Force. Dev Cell. 2017;41(3):228-41.

9. Luo Z, Mu L, Zheng Y, et al. NUMB enhances Notch signaling by repressing ubiquitination of NOTCH intracellular domain. Journal of Molecular Cell Biology. 2020;12(5):345-58.

10. Rong $C$, Feng $Y$, Ye Z. Notch is a critical regulator in cervical cancer by regulating Numb splicing. Oncol Lett. 2017;13(4):2465-70.

11. Tripathi R, Rath G, Sharma V, et al. HES1 Protein Modulates Human Papillomavirus-Mediated Carcinoma of the Uterine Cervix. J Global Oncology. 2019;5:2-10.

12. Dai J, Ma D, Zang S, et al. Cross-Talk Between Notch and EGFR Signaling in Human Breast Cancer Cells. Cancer Invest. 2009;27:533-40.

13. Guo D, Ye J, Dai J, et al. Notch 1 regulates Akt signaling pathway and the expression of cell cycle regulatory proteins cyclin D1, CDK2 and p21 in T ALL cell lines. Leuk Res. 2009;33:678-85.

14. Colombo M, Mirandola L, Maurizio Chiriva-Internati M, et al. Cancer Cells Exploit Notch Signaling to Redefine a Supportive Cytokine Milieu. Front Immunol. 2018;9:1823.

15. Xu C, Zhao H, Chen H, Yao Q. CXCR4 in breast cancer: oncogenic role and therapeutic targeting. Drug Des Devel Ther. 2015;9:4953-64.

16. Tsaouli G, Ferretti E, Bellavia D, et al. Notch/CXCR4 Partnership in Acute Lymphoblastic Leukemia Progression. J Immunol Res. 2019; 1-11.

17. Shi B, Sharifi HJ, Di Grigoli S, et al. Inhibition of HIV early replication by the p53 and its downstream gene p21. Virology Journal. 2018;15:53.

18. lijima K, Yukihito Ishizaka Y. DNA unwinding by Viral Protein R Initializes Complicated Cellular Responses in HIV-1 Infection: Defining the Viper's First Bite. Journal of Emerging Diseases Virology. 2018;4(1):1-11.

19. Ajiro M, Zheng Z-M E6^E7, a Novel Splice Isoform Protein of Human Papilloma virus 16, Stabilizes Viral E6 and E7 Oncoproteins via HSP90 and GRP78. mBio;2015; 6(1): 2068-14.

20. Aster JC, Pear WS, Blacklow SC. The Varied Roles of Notch in Cancer. Ann RevPathol. 2017;12:24575.

21. Barillari G, Pallidino C, Bacigalupo I, et al. Entrance of the Tat protein of HIV-1 into human uterine cervical carcinoma cells causes upregulation of HPV-E6 expression and a decrease in p53 protein levels. Oncology. 2016;12:2389-94. 
22. Schuster-Gossler K, Cordes R, Müller J, et al. Context-Dependent Sensitivity to Mutations Disrupting the Structural Integrity of Individual EGF Repeats in the Mouse Notch Ligand DLL1. Genetics. 2016;202(3):1119-33.

23. Li X, Yu YC, Mu L, Jin F. Upregulation of HES1 Promotes Cell Proliferation and Invasion in Breast Cancer as a Prognosis Marker and Therapy Target via the AKT Pathway and EMT Process. J Cancer. 2018;9(4):757-66.

24. Liu Z, Sanders AJ, Liang G, et al. Hey Factors at the Crossroad of Tumorigenesis and Clinical Therapeutic Modulation of Hey for Anticancer Treatment. Mol Cancer Ther. 2017;16(5):775-86.

25. D'Altri T, Gonzalez J, Aifantis I, et al. Hes1 expression and CYLD repression are essential events downstream of Notch1 in T-cell leukemia. Cell Cycle. 2011;10(7):1031-6.

26. Purow BW, Sundaresan TK, Burdick MJ, et al. Notch-1 regulates transcription of the epidermal growth factor receptor through p53. Carcinogenesis. 2008;29(5):918-25.

27. Laphanuwat P, Likasitwatanakul P, Sittithumcharee G, et al. Cyclin D1 depletion interferes with oxidative balance and promotes cancer cell senescence. $J$ of Cell Science. 2018;131:1-13.

28. Ronchini C, Capobianco AJ. Induction of Cyclin D1 Transcription and CDK2 Activity by Notch ic: $^{2}$ Implication for Cell Cycle Disruption in Transformation by Notch ${ }_{\text {ic. }}$ Mol Cell Biol. 2001;21(17):592534.

29. Bačević K, Lossaint G, Achour TN, et al. Cdk2 strengthens the intra-S checkpoint and counteracts cell cycle exit induced by. DNA damage SciRep. 2017;7:13429.

30. Chowdhury IH, Wang X-F, Landau NR, et al. HIV-1 Vpr Activates Cell Cycle Inhibitor p21/Waf1/Cip1: A Potential Mechanism of G2/M Cell Cycle Arrest. Virology. 2003;305:371-77.

31. Topacio BR, Zatulovskiy E, Cristea S, et al. Cyclin D-Cdk4, 6 Drives Cell-Cycle Progression via the Retinoblastoma Protein's C-Terminal Helix. Mol Cell. 2019;74(4):758-70.

\section{Tables}

Due to technical limitations, tables are only available as a download in the Supplemental Files section.

\section{Figures}




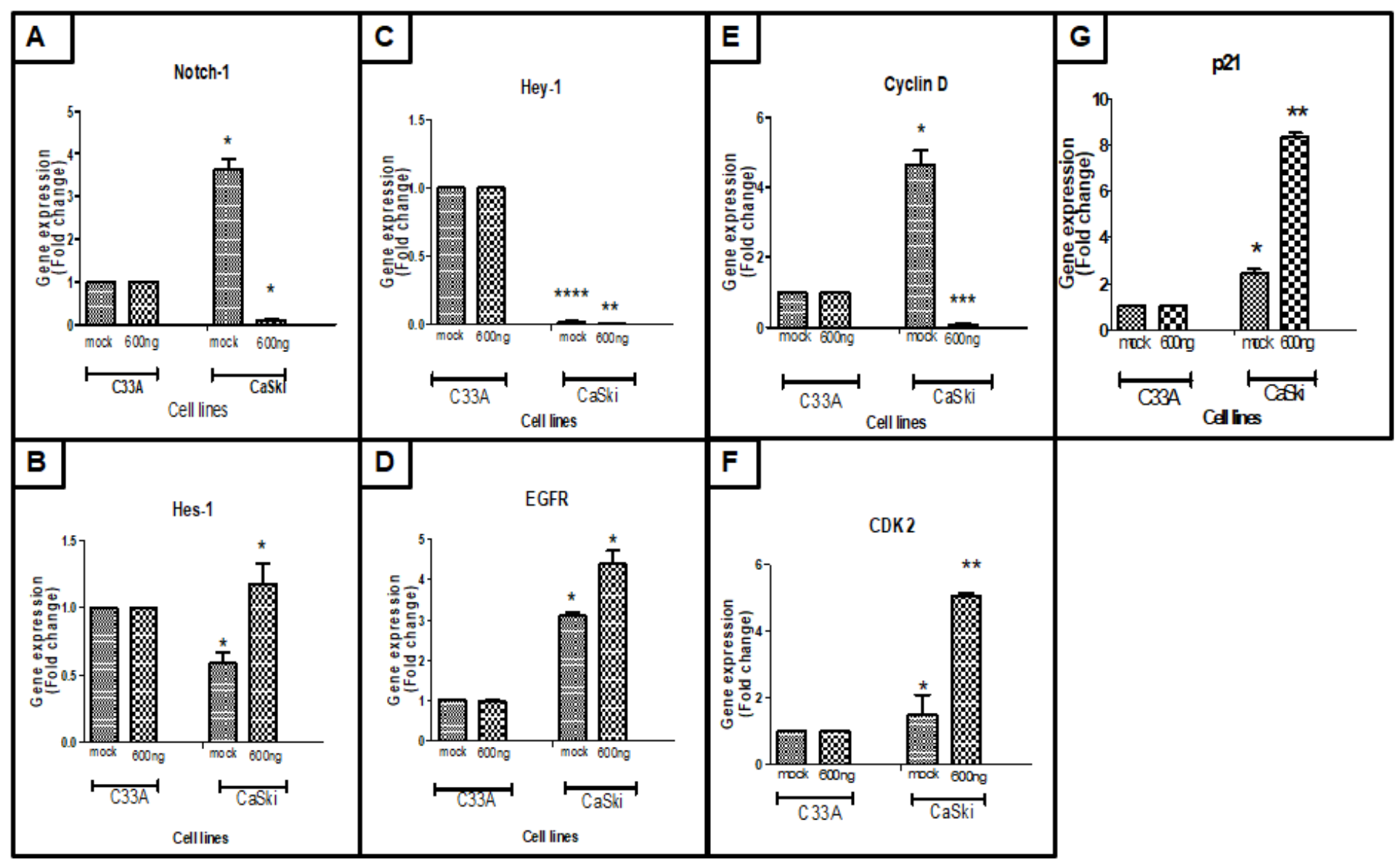

Figure 1

Relative gene expression of HPV-16+ CaSki Cells normalized with HPV negative C33A cells after transfection with Tat DNA. A-G : The $x$-axis shows transfected cell lines with Tat DNA. Mock represents solvent control. Fold change for the following genes was calculated using HPV-16 + CaSki cells (A)Notch-1 and its transcription factors (B)-Hes-1 and (C)-Hey-1 (D)-EGFR (E) -Cyclin D ( F)-CDK2 and (G)p21. Level of significance ${ }^{\star} p<0.05$ was calculated using Student's ' $t$ ' test 


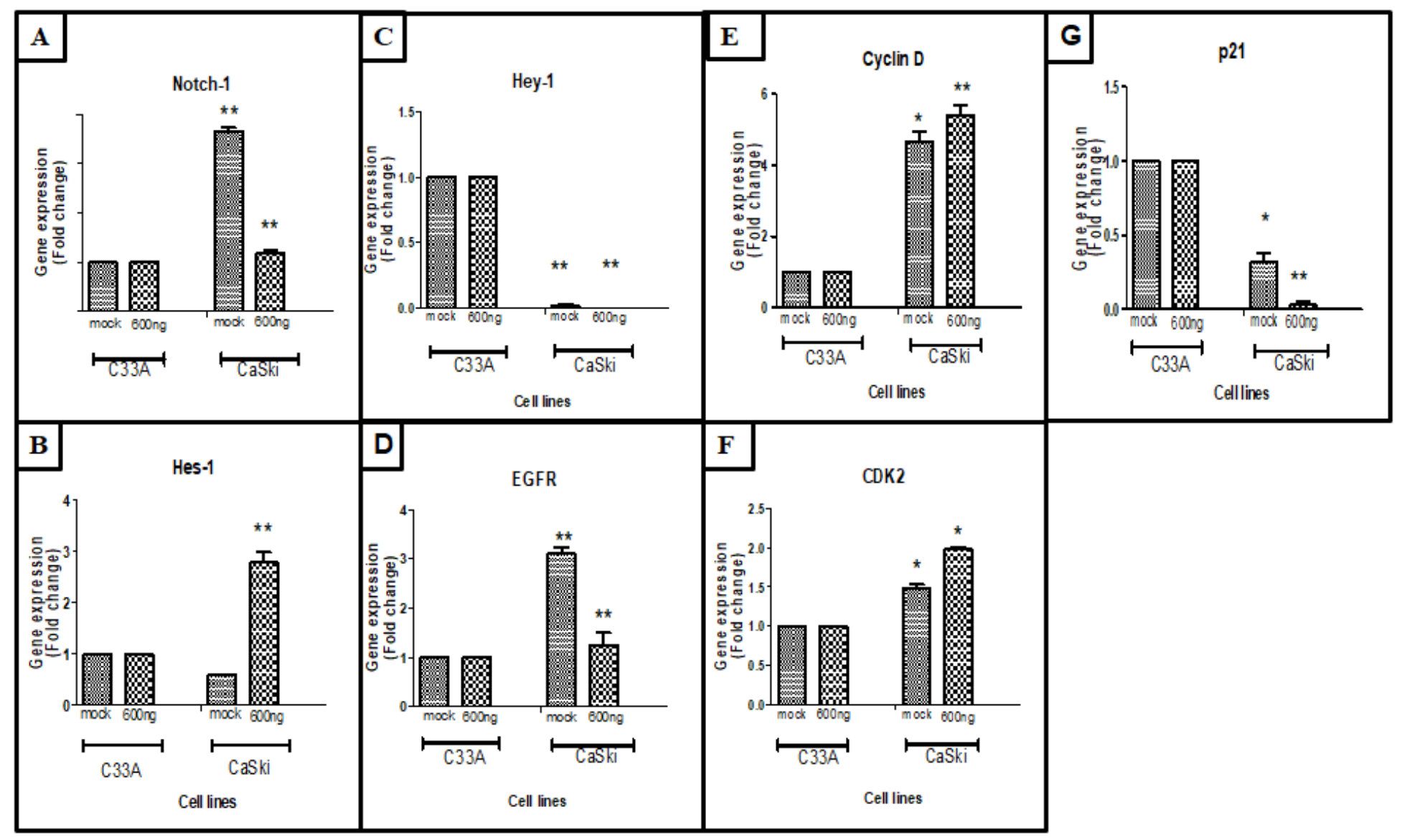

Figure 2

Relative gene expression of HPV-16+ CaSki Cells normalized with HPV negative C33A cells after transfection with HIV-1DNA. A-G : The x-axis shows transfected cell lines with HIV-1 DNA. Mock represents solvent control. Fold change for the following genes was calculated using HPV-16 + CaSki cells (A)-Notch-1 and its transcription factors (B)-Hes-1 and (C)-Hey-1 (D)-EGFR (E) -Cyclin D ( F)-CDK2 and $(G)-p 21$. Level of significance ${ }^{*} p<0.05$ was calculated using Student's 't' test 


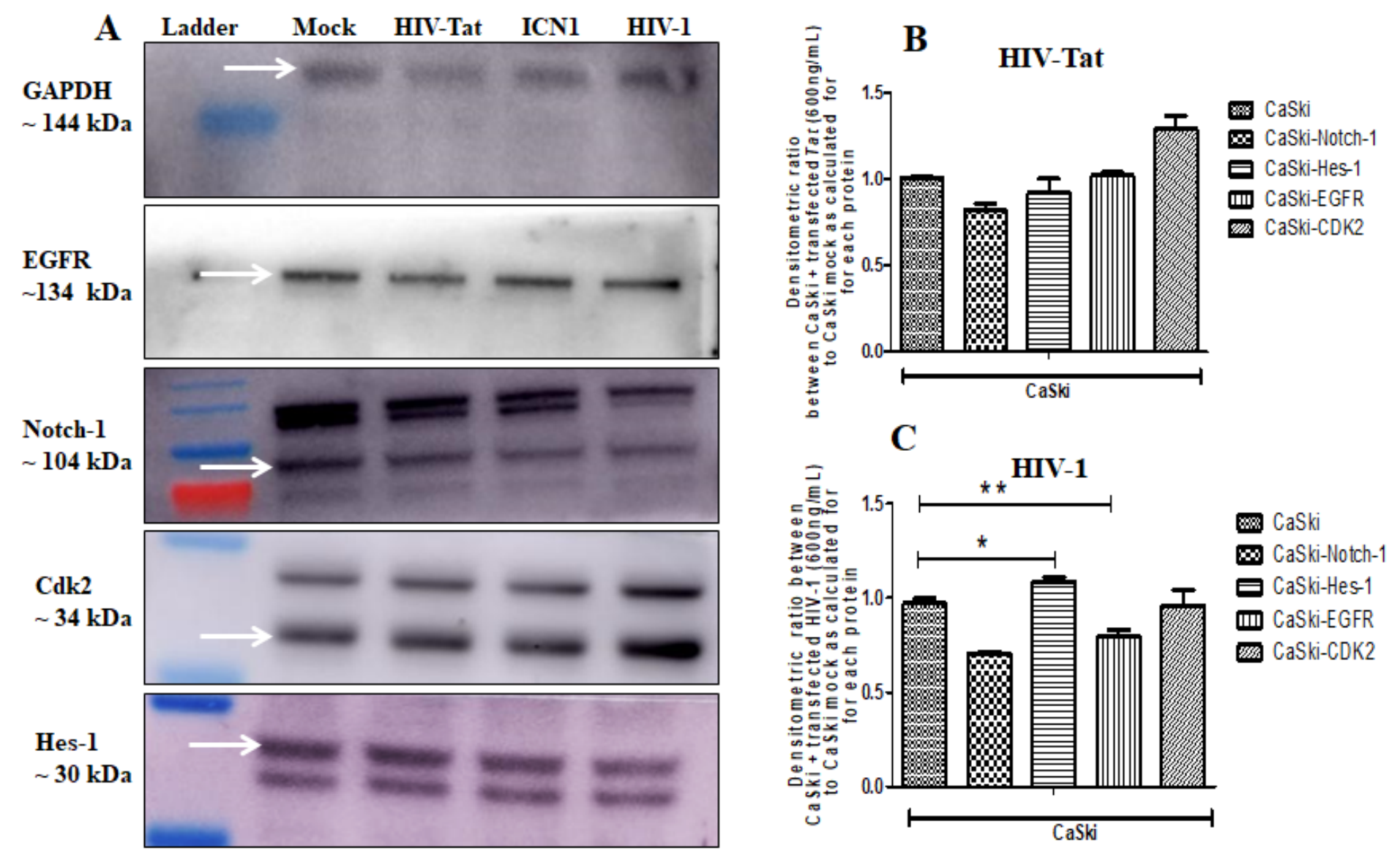

Figure 3

A: Western blotting analysis to assess band density using Image $J$ software for four proteins. GAPDH served as the house keeping gene. Intracellular Notch-1 (ICN1) was taken as positive control. B:

Densitometric ratio of HIV-1 Tat transfected CaSki cells $(600 \mathrm{ng} / \mathrm{mL})$ compared with CaSki mock. Level of significance * $<<0.05$ was calculated using Student's 't' test . C:Densitometric ratio of HIV- 1 transfected CaSki cells $(600 \mathrm{ng} / \mathrm{mL})$ compared with CaSki mock. Level of significance ${ }^{*} \mathrm{p}<0.05$ was calculated using Student's 't' test 


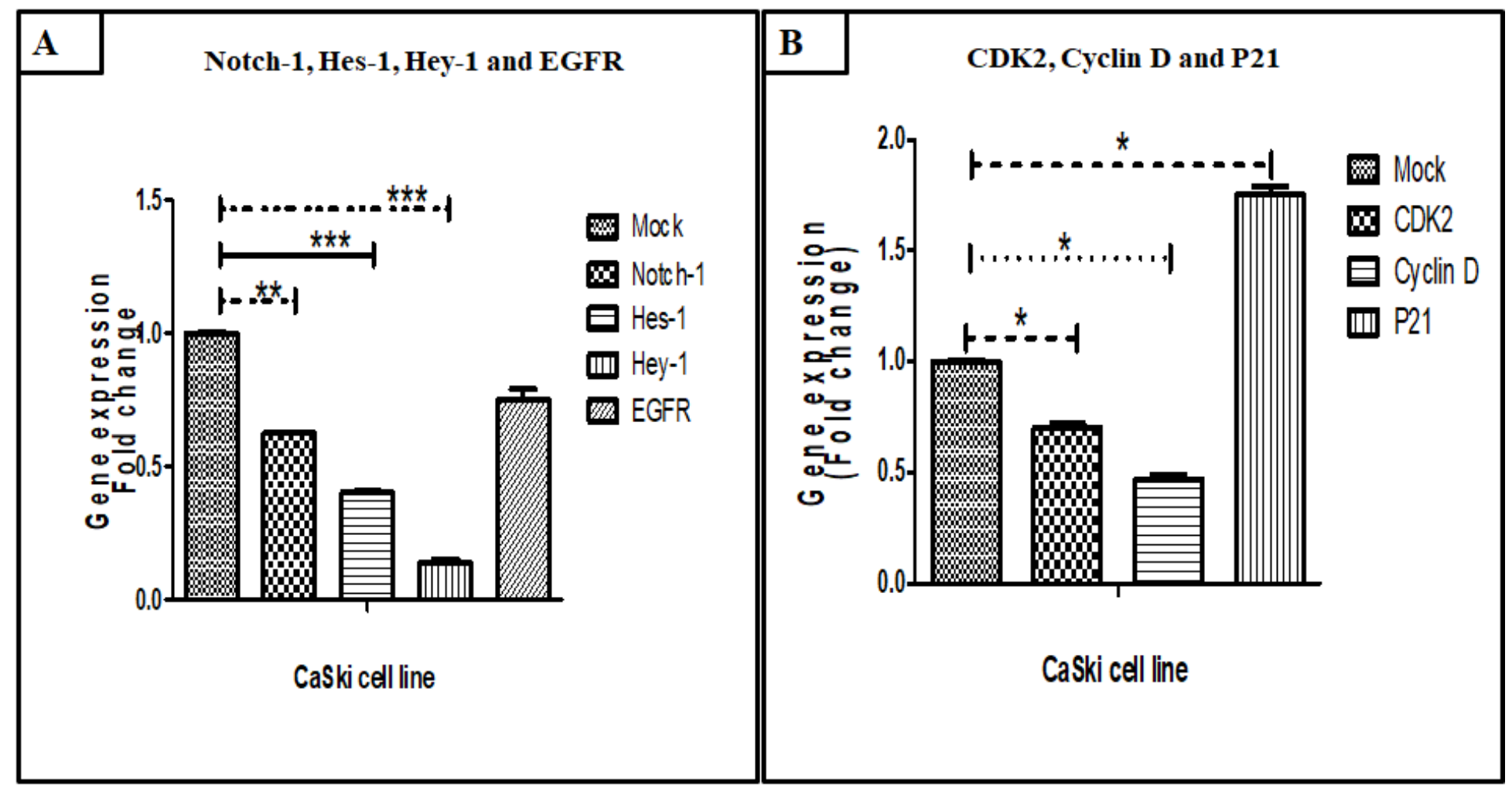

Figure 4

A : Mock represents solvent control used in preparation of $62.5 \mathrm{mM} / \mathrm{LDAPT}$, a Notch-1 inhibitor. X-axis represents the relative gene expression (fold change) for mock, Notch-1, Hes-1, Hey-1 \& EGFR. Level of significance * $p<0.05$ was calculated using Student's ' $t$ ' test. B : Mock represents solvent control used in preparation of $62.5 \mathrm{mM} / \mathrm{LDAPT}$, a Notch-1 inhibitor. X-axis represents the relative gene expression (fold change) for mock, cyclin D, CDK2 \& p21. Level of significance * $p<0.05$ was calculated using Student's ' $t$ ' test 


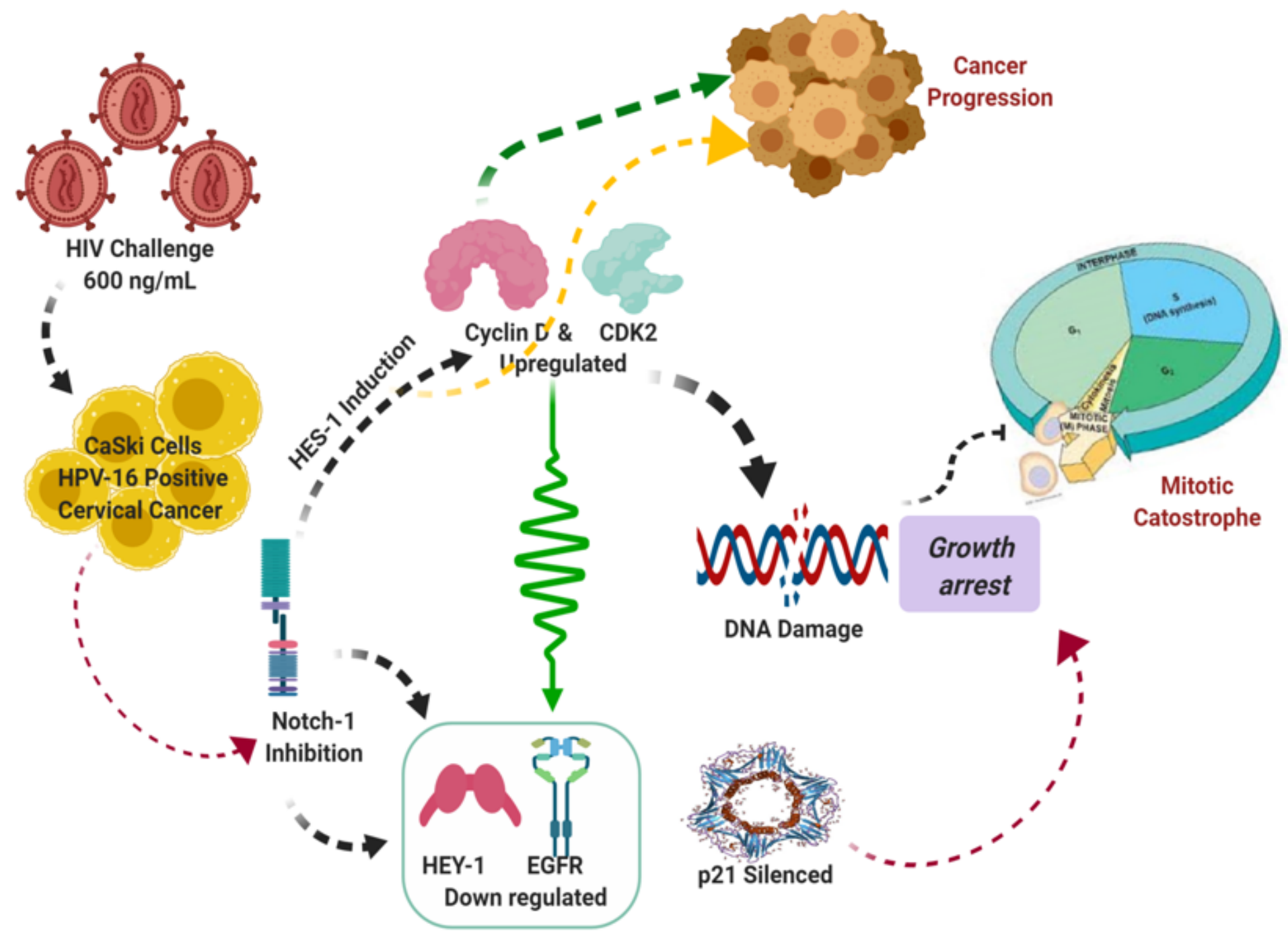

Figure 5

Graphical Abstract showing how HIV interacts with HPV16 to induce Notch-1 suppression for cancer progression. ( Created with BioRender.com)

\section{Supplementary Files}

This is a list of supplementary files associated with this preprint. Click to download.

- TABLES.pptx

- SUPPLEMENTARYDATA24032021.pptx 